\title{
Variation of Alginate: Carboxymethyl Cellulose on Making Beads CMC from Cellulose of Corn Stalk
}

\author{
Anggun Pertiwi ${ }^{1, *}$ Eny Yulianti ${ }^{2,}$ Lilik Miftahul Khoiroh ${ }^{2,}$ Febi Yusniyanti ${ }^{2}$
}

\author{
${ }^{1}$ chemistry department, Sains and technology Faculty, UIN Maulana Malik Ibrahim, Malang, Indonesia, 65144 \\ ${ }^{2}$ chemistry department, Sains and technology Faculty, UIN Maulana Malik Ibrahim, Malang, Indonesia, 65144 \\ *Corresponding Author. Email: angguncahya19@gmail.com
}

\begin{abstract}
Synthesize CMC uses cellulose extracted from cornstalk waste. FTIR and XRD characterize CMC synthesize. Alginate: CMC (AC) beads made by dropping technique through the ionic gelation method with crosslinking $\mathrm{CaCl} 23 \%$. Fourier Transform Infra-Red (FTIR) to know the AC's function group, swelling test to know the swelling power, and SEMEDX to see the surface characteristics. The optimum composition of AC composite beads was 1:2 based on beads formation, the highest swelling power value $175.5 \%$, and the diameter was $26.64 \%$. The data FTIR AC showed that wave number at $819 \mathrm{~cm}-1$ indicates the presence of Ca-alginate linkage. The SEM-EDX of AC without CMC 1:0 showed a smooth surface, while the surfacer character of AC 1:2 is rough.
\end{abstract}

Keywords: alginate-carboxymethyl cellulose, beads, cornstalk

\section{INTRODUCTION}

In Indonesia, corn requirements always increase year to year. Nationally, the agriculture ministry states that along 2012-2016, east Java is on the first rank of the biggest corn producer for about $32.06 \%$. All this time, corn utilization focuses on the seeds, while the other part, as stalk and cob, does not utilize maximally. As a result, be agriculture waste. According to [1][2], corn stalk contain of $42.6 \%$ cellulose, $8.2 \%$ lignin, $21.3 \%$ hemicellulose, and $9-11 \%$ is water. By containing cornstalk has a high potency to be modified, increasing the utility and economy.

Biopolymer composite from alginate and carboxymethyl cellulose is more effective on bead than flake form. It causes bead form has higher adsorption capacity and diffusion character [3], faster adsorption kinetics[4], and a more significant surface area[5]. Adsorption power depends on the composition. One of the biopolymers used to form bead is sodium alginate. Sodium alginate is a biodegradable and biocompatible material. It has high hydrophilicity and has an active site to bond with the multivalent cation hydroxyl group [6]. However, alginate has low stability so that alginate easily degradation terminally [7]. Therefore, utilization alginate must react as copolymerization with other materials as
CMC. CMC has high hydrophilicity; non-toxic, biodegradable, has viscosity for about $700-1500 \mathrm{mPa}$ with DS 0.6-0.95 [8]

The composition ratio of alginate and cellulose on making beads is influential on adsorption power. Using cellulose $10-25 \%$ can increase adsorption from $68 \%$ by $80 \%$, while the adsorption beads by using alginate $100 \%$ are just $19 \%$ [6]. Mentioned to [7] that beads with alginate $100 \%$ have low porosity and rough, then beads with alginate CMC 1:1 has a hard surface and high porosity. Too high CMC concentrations cause morphologically compact and influence swelling power. [9] state that too high CMC for forming beads can produce beads with morphologically compact and hinder diffusion.

Based on that information on making bead with composition alginate: $\mathrm{CMC}$ needs to know the optimum condition of beads. In this research, corn stalk will modify cellulose beads with a variation ratio of $1: 0,1: 1$, $1: 2$, and $1: 3$ with adding crosslink agent $\mathrm{CaCl}_{2} 3 \%$. Cellulose from extraction and $\mathrm{CMC}$ synthesize characterized with XRD and determination best composition beads based on swelling power gravimetrically and the optical microscope, FTIR characterization to know function group, and SEM-EDX to know surface morphology of beads. 


\section{MATERIALS AND METHOD}

\subsection{Material}

Cornstalk waste, sodium hydroxide p.a (Merck), hydrochloride acid p.a (Merck), sodium monochloro acetic p.a (Merck), methanol p.a (Merck), calcium chloride p.a (Merck), sodium chlorite p.a (Merck), acetic acid p.a (Merck), sodium alginate (Phyto), methylene blue p.a (Merck), aqua demineralization, and distilling water.

\subsection{Method}

\subsubsection{Extraction of Cellulose from Cornstalks}

25-gram cornstalk powder was added $500 \mathrm{~mL} \mathrm{NaOH}$ $20 \%$ at $80 \mathrm{oC}$ for $90 \mathrm{~m}$ then washed with distilled water. After that, samples bleach with $100 \mathrm{~mL}$ of $\mathrm{NaClO} 21 \%$ and $\mathrm{CH} 3 \mathrm{COOH}, 10 \%$ till $\mathrm{pH}$ five at $75 \circ \mathrm{C}$ for an hour, then washed with distilled water until $\mathrm{pH}$ neutral. Pulps were hydrolyzed with 5\% hydrochloride acid under reflux at $950 \mathrm{C}$ for an hour; then, the hydrolyzed pulps were washed with distilled water and dried at room temperature [10]. Then samples characterize with FTIR and XRD.

\subsubsection{Preparation of Carboxymethyl Cellulose}

Five grams of cellulose added with $100 \mathrm{~mL}$ water distillation and $10 \mathrm{~mL}$ sodium hydroxide $30 \%$ drop by drop for an hour under constant stirring - etherification with five-gram sodium monochloro acetic under continuous stirring and at $60^{\circ} \mathrm{C}$ for three hours. The product obtained was filtered and suspended with 100 $\mathrm{mL}$ methanol for $1 \mathrm{~d}$. then the samples were neutralized with acetic acid and filtered to get residue products. After that, the product was dried by oven at $60^{\circ} \mathrm{C}$ until constant weight [11]. Finally, the product was characterized by FTIR and XRD to know the character.

\subsubsection{Determination of the Best Composition of Alginate: CMC in Making Beads}

Beads made by mixing sodium alginate and $\mathrm{CMC}$ with different compositions $0: 1,1: 0,1: 1,1: 2$, dan 1:3 $(\mathrm{g} / \mathrm{g})$ by combining two biopolymers under constant stirring at room temperature until the solution be homogeneous. The formation of beads uses a gelation technique using a syringe needle dropwise from a distance of $3 \mathrm{~cm}$ into $\mathrm{CaCl} 23 \%$. Beads were formed instantly and were left in contact with $\mathrm{CaCl} 23 \%$ for $1 \mathrm{~d}$ to complete the gelation. The beads that formed rinsed gently with aqua demineralization and dried at $37^{\circ} \mathrm{C}$ [9], [12]. Finally, beads characterized swelling power gravimetrically and the optical microscope, FTIR, and surface morphology with SEM EDX.

\subsubsection{Characterization}

\section{$\underline{2.2 .4 .1 X R D}$}

X-ray diffraction applied to observe changes in cellulose and CMC. X-ray diffraction of product cellulose and CMC synthesize measure with X-ray diffractometer X'pertPRO PANalytical and recorded with $\mathrm{Cu} \mathrm{K} \alpha \lambda=1,54056 \AA(40 \mathrm{kV}, 30 \mathrm{~mA})$. Samples scanned from $0^{\circ}-60^{\circ}$

\subsubsection{Characterization of Functional Groups}

Determination function group of AC variation using FTIR (VARIAN type FT 1000). Approximately beads were grinned with $\mathrm{KBr}$ using mortar agate and pressed in a pellet. Then put in the sample holder and measure the wavenumber of the function group [13].

\subsubsection{Swelling AC Beads Test}

Monitoring the water sorption process use gravimetric procedure and optical microscope[14]. \pm 50 $\mathrm{mg}$ beads alginate: CMC suspended with10 mL aqua demineralization for $1 \mathrm{~d}$. The swollen beads weighed on a digital balance. calculating the swelling ratio and diameter using the following equation Swelling ratio (\%) $=(\mathrm{Wf}-\mathrm{Wi}) / \mathrm{Wi} \times 100 \%$

$\mathrm{Wf}$ is the final weight, and $\mathrm{Wi}$ is the initial weight of AC

Diameter $(\%)=(D f-D i) /$ Di $x 100 \%$

Df is the final diameter, and Di is the initial diameter of AC.

\subsubsection{Methylene Blue Adsorption}

AC has suspended with methylene blue solution 50 ppm for $17 \mathrm{~d}$. Then measure the absorbance with spectrophotometer UV-Vis (VARIAN) on $665.0 \mathrm{~nm}$.

\subsubsection{Characterization of Surface Morphology}

The study micrograph of AC uses a scanning electron microscope (JEOL JSM 6510LA). (Anggraeni, 2008). This analysis is for AC optimum and control.

\section{RESULT AND DISCUSSION}

\subsection{Cellulose extraction}

The first step of cellulose extraction is lignification using sodium hydroxide $10 \%$ solution to dissolve noncellulose. Lignification cannot remove lignin as a whole is characterized by pulp production, which is still brown. In contrast, the loss of lignin is from the presence of black liquor leachate - the results of the adsorption band from each extraction step in cellulose extraction as Figure 1. The loss of noncellulose components supports the absent peak at $1513 \mathrm{~cm}-1$ containing aromatic $\mathrm{C}=\mathrm{C}$ 
groups from lignin. Reducing the intensity at $1733 \mathrm{~cm}-1$ indicates that the amount of group hemicellulose decreased. The intensity of the wavenumber $896 \mathrm{~cm}-1$ is the absorption character of $\beta$-glycosides. This information has similarities with standard cellulose in research [15].

\subsection{Making Carboxymethyl Cellulose}

There are two steps to making CMC, that is alkalization and carboxymethylation. In alkalization, cellulose reacts with sodium hydroxide to form sodium cellulose. The Hydroxyl group attacks the $\mathrm{H}$ atom on $\mathrm{OH}$ C3, C6, or C2 cellulose by releasing $\mathrm{H} 2 \mathrm{O}$, which causes the $\mathrm{OH}$ group of cellulose to inactive and swell. So, the monochloro acetate easy to diffuse on the carboxymethylation process. Based on physical observations, the produces of CMC synthesis is not too different from cellulose extracted. The colour is yellowish-white to very young cream. However, the FTIR characterization shows a sharper absorption at the wavenumbers of 1596 and $1413 \mathrm{~cm}^{-1}$. That indicates the amount of carboxyl group at CMC synthesis increases after carboxymethylation of replacing the hydroxyl group in cellulose. FTIR synthesis CMC spectra profile has similarities with standard CMC as in the study [16].

The cellulose and CMC X-ray diffraction showed that cellulose has high crystallinity. That is because the extraction cellulose step can remove amorphous compounds as lignin and hemicellulose. That is an agreement with research [15] and [17]. The CMC diffractogram is almost the same as the cellulose peak with additional peaks at positions 32 and $45^{\circ}$, which show the CMC character. These results are similar to the previous research of [18][19][20][21].

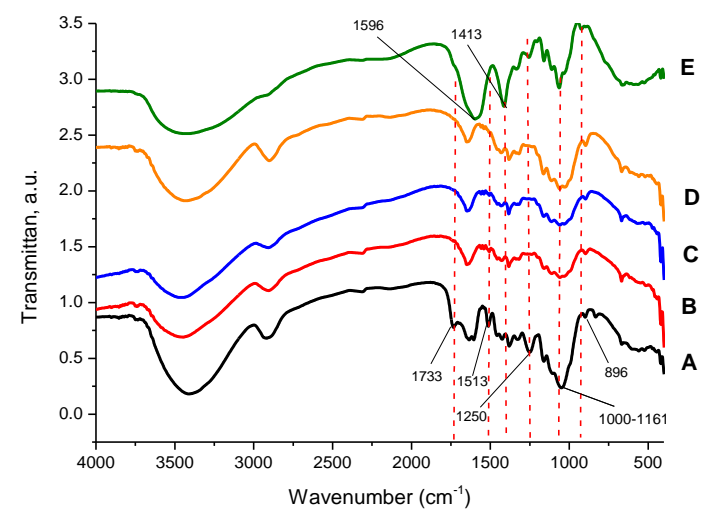

Figure 1. IR spectra of (a) corn stalk, (b) lignification, (c) bleaching, (d) extracted cellulose and (e) CMC synthesis



Figure 2. Difraktogram XRD (a) cellulose (b) CMC synthesis

\subsection{Optimum Composition of Alginate: CMC in Making Beads}

Table 1. Optical microscope dry and wet beads with magnification $0,75 \times 10$

\begin{tabular}{|c|c|c|}
\hline & Dry & Wet \\
\hline AC 1:0 & & \\
\hline AC $1: 1$ & & \\
\hline AC $1: 2$ & & \\
\hline AC $1: 3$ & & \\
\hline
\end{tabular}

It was making Alginate: CMC (AC) beads by dropping technique through the ionic gelation method with crosslinking $\mathrm{CaCl}_{2} 3 \%$. Determining the optimum 
composition of $\mathrm{AC}$ is based on the formation of beads, power swelling calculated gravimetrically, and optical microscopy with ImageJ application's help to measure the increase in diameter and the adsorption of methylene blue dyes. In the composition of beads, 0:1 is not able to form beads formation. The composition consists only of a CMC matrix, while the fibre that acts as a bead formation that is alginate does not exist. Therefore, it cannot form spherical as bead formation when dropping the viscose solution into a crosslink solution.

AC beads 1:2 have a more spherical shape. Besides, the composition also has the highest swelling, and diameter increases with increasing time. Methylene blue adsorption result reinforces that result. For eleven and sixteen days, the AC 1: 2 adsorption beads had the highest adsorption ability. On the day after that, the adsorption was almost constant, and there was no significant difference. In the five-day immersion, the adsorption process was slow, so that the number of $\mathrm{MB}$ adsorbed in beads was only slightly. That is because, at the beginning of the MB adsorption process, it only reaches the beads limiting screen, and the longer the immersion time, the MB successfully diffuses on the surface and pore structure of the beads. Finally, the active site of the AC beads is the negatively charged carboxylic group capable of binding to cations in MB. The determination of methylene blue adsorption concentration uses a standard curve in the equation $\mathrm{y}=$ $0.5384 \mathrm{x}-0.0075$ with a maximum wavelength of 665.0 $\mathrm{nm}$.
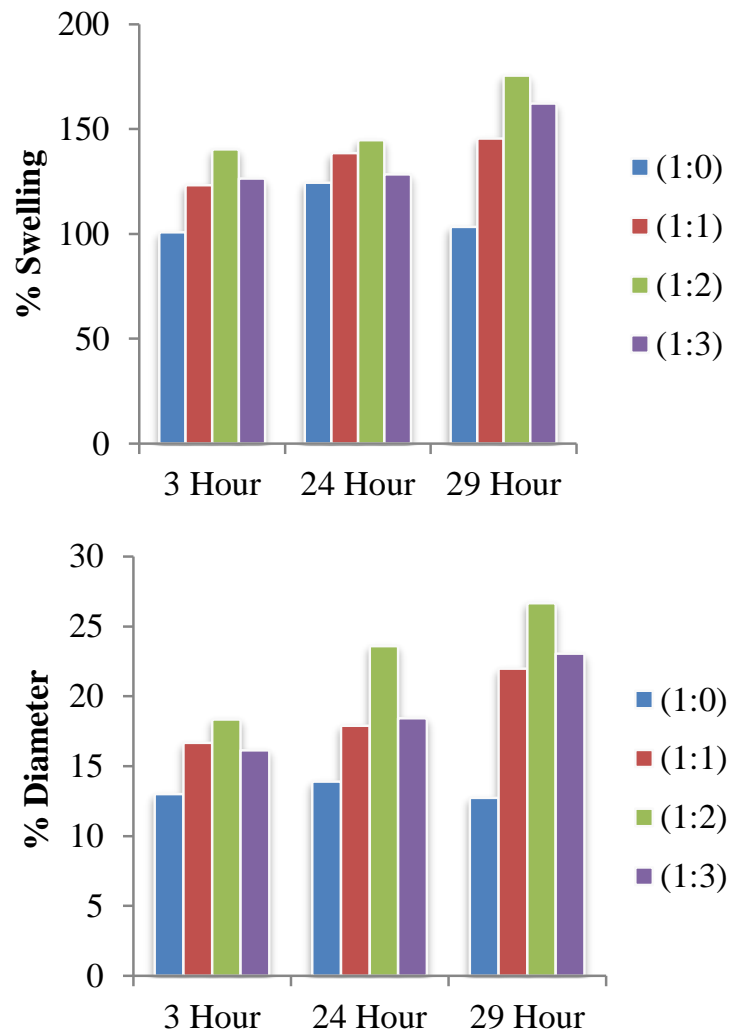

Figure 3. \% swelling and diameter AC swollen beads graph

\subsubsection{Methylene Blue Adsorption Activity}

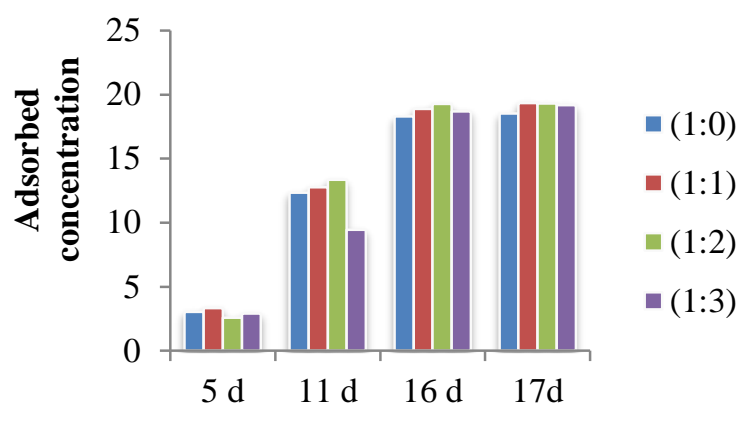

Figure 4. Graph of methylene blue adsorption

The observation of swelling and adsorption of methylene blue in AC explained that swelling power and adsorption ability increased with CMC. CMC is hydrophilic and has a carboxylic group. Suppose the concentration increases in $\mathrm{AC}$, enhanced repulsion between carboxylic group ion causes the network chains to undergo a more considerable relaxation, resulting in a more considerable swelling and methylene blue adsorption. However, when CMC's concentration becomes high, the increased number of carboxyl group chains produces a dense network and causes retention of mobility, and slow the diffusion process [22][23]. The analysis results using FTIR showed that the higher CMC concentrations used in the AC composite resulted in sharper peaks in the wavenumber region of 1400-1600 $\mathrm{cm}^{-1}$, the $\mathrm{C}=\mathrm{O}$ asymmetric symmetrical character the CMC.

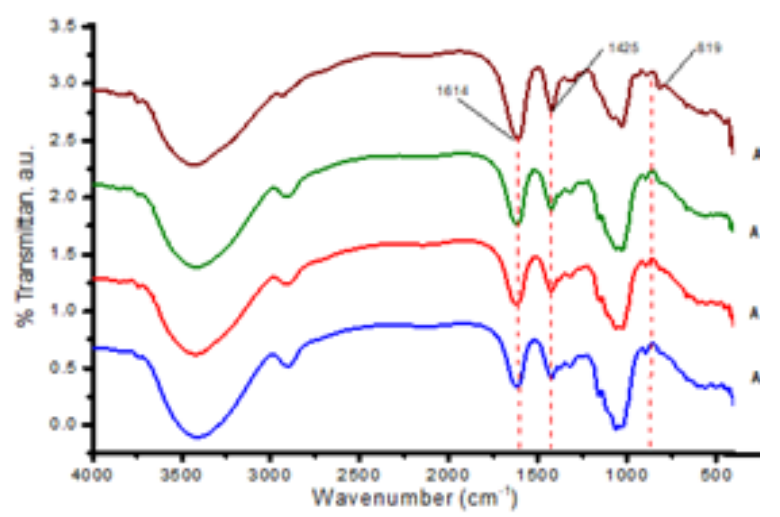

Figure 5. IR spectra of 1:0, 1:1, 1:2, and 1:3 beads

In contrast, the other groups in each AC composition not significantly different. The other groups that appear are in the region of wave number $3412-3426 \mathrm{~cm}^{-1}$, the $\mathrm{OH}$ group's character, the $\mathrm{CH}$ vibration at $2917-2932 \mathrm{~cm}^{-1}$, $1027-1032 \mathrm{~cm}^{-1} \mathrm{CO}$ stretch $1315-1318 \mathrm{~cm}^{-1}$ character $\mathrm{OH}$ stretch as well. The success of the bond between the crosslink $\mathrm{Ca} 2+$ and alginate seen at wavenumber that appears in the region $819 \mathrm{~cm}^{-1}$. 
Table 2. Persen element in beads

\begin{tabular}{llllll}
\hline \multirow{2}{*}{ Sample } & \multicolumn{6}{l}{ Weight of each element (\%) } \\
\cline { 2 - 6 } & C & O & Ca & Na & Cl \\
\hline AC 1:0 & 46,58 & 47,57 & 3,06 & 0,90 & 1,89 \\
AC 1:2 & 48,91 & 45,87 & 2,69 & 0,80 & 1,74 \\
\hline
\end{tabular}

It was determining the content of elements present in AC use EDX. The results showed that the calcium concentration in $\mathrm{AC}$ 1: 0 was higher than $\mathrm{AC} 1: 2$. On the $\mathrm{AC}$ surface, $100 \%$ alginate only contains alginate and $\mathrm{Ca}$, while on the AC surface, 1: 2 besides containing alginate also includes CMC. The surface of beads made of cellulose will have a surface that is closed with cellulose [24], and according to [25], beads with $100 \%$ alginate will form a membrane with $\mathrm{Ca}$. Therefore, in $\mathrm{AC} \mathrm{1:} \mathrm{0,}$ there will be more possibility of $\mathrm{Ca}$ being found on its surface. On the other hand, $\mathrm{AC}$ 1: 0 has fewer $\mathrm{C}$ elements than AC 1:2. That result proves that the addition of CMC in the manufacture of air conditioners will increase element $\mathrm{C}$.

\section{CONCLUSION}

IR spectra of CMC synthesis showed sharper peaks at $1596 \mathrm{~cm}-1$ than peaks in cellulose also XRD cellulose and CMC diffractograms almost equal to the addition of $32^{\circ}$ and $45^{\circ}$ peaks in CMC. The best AC composition is $1: 2$ with the most considerable weight and diameter of $175.5 \%$ and $26.64 \%$, respectively, in which the characterization of the surface is rough.

\section{AUTHORS' CONTRIBUTIONS}

Eny Yulianti provided ideas and explored the literature on the potential of corn stalks as bio adsorbents. Anggun Cahyaning Pertiwi conducted sample preparation and collected research data. Lilik Miftakhul Khoiroh discussed the analysis of the XRD characterization results and determining the optimum composition of the beads making, as well as Febi Yusniyanti analyzed the results of the characterization of FTIR and SEM-EDX. All authors provided feedback on the results of the research analysis and scriptwriting.

\section{ACKNOWLEDGMENTS}

Chemistry department of sains and technology faculty, UIN Maulana Malik Ibrahim Malang, Indonesia support this work.

\section{REFERENCES}

[1] G. Lv and S. Wu, “Analytical Pyrolysis Studies of Corn Stalk and its Three Main Components by TG-MS and Py-GC/MS," Journal of Analytical and Applied Pyrolysis, vol. 97, pp. 11-18, Sep. 2012.

[2] T. Shui et al., "Synthesis of Sodium Carboxymethyl Cellulose Using Bleached Crude
Cellulose Fractionated from Cornstalk," Biomass and Bioenergy, vol. 105, pp. 51-58, Oct. 2017.

[3] Z. Lou et al., "Contribution of Tertiary Amino Groups to Re(VII) Biosorption on Modified Corn Stalk: Competitiveness and Regularity," Bioresource Technology, vol. 133, pp. 546-554, Apr. 2013.

[4] D. W. O'Connell, C. Birkinshaw, and T. F. O’Dwyer, "Heavy Metal Adsorbents Prepared from the Modification of Cellulose: A review," Bioresource Technology, vol. 99, no. 15, pp. 6709-6724, Oct. 2008.

[5] J. Trygg, P. Fardim, Åbo akademi (1918- ), Laboratoriet för fiber- och cellulosateknologi, and Åbo akademi (1918- ), "Functional Cellulose Microspheres for Pharmaceutical Applications," 2015.

[6] G. Bayramoglu, "Biosorption of Heavy Metal Ions on Immobilized White-rot Fungus Trametes Versicolor," Journal of Hazardous Materials, vol. 101, no. 3, pp. 285-300, Aug. 2003.

[7] S. M. Ibrahim, F. I. Abou El Fadl, and A. A. ElNaggar, "Preparation and Characterization of Crosslinked Alginate-CMC Beads for Controlled Release of Nitrate Salt," Journal of Radioanalytical and Nuclear Chemistry, vol. 299, no. 3, pp. 1531-1537, Mar. 2014.

[8] M. Sönmez, A. Ficai, D. Ficai, R. Trusca, and E. Andronescu, "Alginate/Cellulose Composite Beads for Environmental Applications," p. 12, 2016.

[9] H. Ren, Z. Gao, D. Wu, J. Jiang, Y. Sun, and C. Luo, "Efficient Pb (II) Removal Using Sodium Alginate-Carboxymethyl Cellulose Gel Beads: Preparation, Characterization, and Adsorption Mechanism," Carbohydrate polymers, vol. 137, pp. 402-409, 2016.

[10] M. Gericke, J. Trygg, and P. Fardim, "Functional cellulose beads: Preparation, Characterization, and Applications," Chemical reviews, vol. 113, no. 7, pp. 4812-4836, 2013

[11] F.-C. Wu, R.-L.Tseng, and R.-S. Juang, "Comparative Adsorption of Metal and Dye on Flake- and Bead-Types of Chitosans Prepared from Fishery Wastes," Journal of Hazardous Materials, vol. 73, no. 1, pp. 63-75, Mar. 2000.

[12] R. Nurmasari, U. T. Santoso, D. Umaningrum, and T. Rohman, "Immobilization Of Humic Acid on Chitosan Beads by Protected Cross-Linking Method and Its Application As Sorbent for Pb(Ii)," p. 8, 2010.

[13] L. K. Voon, S. C. Pang, and S. F. Chin, "Highly Porous Cellulose Beads of Controllable Sizes 
Derived from Regenerated Cellulose of Printed Paper Wastes," Materials Letters, vol. 164, pp. 264-266, Feb. 2016.

[14] T. Dewangan, A. Tiwari, and A. K. Bajpai, "Adsorption of $\mathrm{Hg}(\mathrm{II})$ Ions onto Binary Biopolymeric Beads of Carboxymethyl Cellulose and Alginate," Journal of Dispersion Science and Technology, vol. 31, no. 6, pp. 844-851, May 2010.

[15] Y. Liu, W. Wang, Y. Jin, and A. Wang, "Adsorption Behavior of Methylene Blue from Aqueous Solution by the Hydrogel Composites Based on Attapulgite," Separation Science and Technology, vol. 46, no. 5, pp. 858-868, Mar. 2011.

[16] H. A. Begum and M. K. B. Mahbub, "Effectiveness of Carboxymethyl Cellulose for the Removal of Methylene Blue from Aqueous Solution," Dhaka University Journal of Science, vol. 61, no. 2, pp. 193-198, Nov. 2013.

[17] A. F. Hassan, A. M. Abdel-Mohsen, and M. M. G. Fouda, "Comparative study of calcium alginate, activated carbon, and their composite beads on methylene blue adsorption," Carbohydrate Polymers, vol. 102, pp. 192-198, Feb. 2014.

[18] S. Suvachittanont and W. Pookingdao, "Development of Porous Spherical Cellulose Bead Production from Corn Cob as an Exfoliating Agent for Cosmetic Industries,” p. 8, 2013.

[19] N. Nur'ain, N. Nurhaeni, and A. Ridhay, "Optimasi Kondisi Reaksi untuk Sintesis Karboksimetil Selulosa (CMC) dari Batang Jagung (Zea Mays L.)," KOVALEN, vol. 3, no. 2, p. 112, Sep. 2017.
[21] E. F. Lessa, M. S. Gularte, E. S. Garcia, and A. R. Fajardo, "Orange Waste: A Valuable Carbohydrate Source for The Development of Beads with Enhanced Adsorption Properties for Cationic Dyes," Carbohydrate Polymers, vol. 157, pp. 660-668, Feb. 2017.

[22] S. Suvachittanont and W. Pookingdao, "Development of Porous Spherical Cellulose Bead Production from Corn Cob as an Exfoliating Agent for Cosmetic Industries,” p. 8, 2013.

[23] N. Rehman, M. I. G. de Miranda, S. M. L. Rosa, D. M. Pimentel, S. M. B. Nachtigall, and C. I. D. Bica, "Cellulose and Nanocellulose from Maize Straw: An Insight on the Crystal Properties," Journal of Polymers and the Environment, Nov. 2013.

[24] G. Lv and S. Wu, "Analytical Pyrolysis Studies of Corn Stalk and Its Three Main Components By TG-MS and Py-GC/MS," Journal of Analytical and Applied Pyrolysis, vol. 97, pp. 11-18, Sep. 2012.

[25] Md. I. H. Mondal, Mst. S. Yeasmin, and Md. S. Rahman, "Preparation of Food Grade Carboxymethyl Cellulose from Corn Husk Agrowaste," International Journal of Biological Macromolecules, vol. 79, pp. 144-150, Aug. 2015. 